ORIGINAL ARTICLE

\title{
The Relationship between Resettlement and Birth Rates: The Case of Gambella, Ethiopia
}

\author{
Aynalem Adugna ${ }^{1}$, Helmut Kloos ${ }^{2}$
}

ABSTRACT

BACKGROUND: This study aims to examine the possible impacts of resettlement on birth rates by using the length of stay variable in the 2000 Demographic and Health Survey (DHS). METHODS: Data in all three rounds of Gambella Administrative Region's Demographic and Health Surveys (DHS) are analyzed. The neighboring administrative region of Benishangul-Gumuz is used as a control. The multivariate analysis of variance (MANOVA) is applied with duration of residence as a categorical independent variable. The statistical software SAS is used. RESULTS: In a univariate analysis of Gambella's DHS 2000, duration of residence has a significant effect on mothers' age at first birth $(p<0.001)$, the number of children born within the five years of the survey ( $p<0.001)$, and the total number of children ever born $(P<0.001)$. In the MANOVA analysis, the duration effect on all three is also statistically significant $(p<0.001)$. DISCUSSION: Resettlement had a disruptive effect on birth rates among females who were just coming into marriageable ages in places of origin but were resettled to Gambella. Although the disruptive effects waned over time, the initial shortfall resulted in reduced overall lifetime births for settler women who were not past the midpoint of their reproductive years at arrival. CONCLUSION: Based on the reproductive history of female settlers with different duration of residence in the resettlement schemes, we recommend the reinstatement of the length of residence question in future DHS surveys in Ethiopia to allow a longitudinal tracking of demographic trends among nonnative populations.

DOI: http://dx.doi.org/10.4314/ejhs.v26i4.8

\section{INTRODUCTION}

Three Demographic and Health Surveys (DHS) were conducted in Ethiopia, in 2000, 2005 and 2011. Results of these surveys were reported at the national level (1-3), allowing examinations of demographic patterns (4-9) and topic-specific analyses $(10,11)$. This has helped close some knowledge gaps. However, the demographic impacts of population mobility on fertility and mortality have not been analyzed. As a result, the short- and long-term demographic impacts of migrations, in particular, the impacts of government-sponsored resettlement of the 1980s, 1990s, and 2000s remain largely unknown. This study aims to help fill this knowledge gap using a point-in-time analysis together with a longitudinal approach that compares reported numbers of births for settlers and non-settlers in Gambella Administrative Region. Gambella Region was selected because it tops the list of destinations of government-sponsored resettlement dating back to the 1970s (12). The neighboring region of Benishangul-Gumuz served as a control (Figure 1). Both regions have hosted settlers, refugees and internally displaced persons over the years, and have similar lowland climates and vegetations (1320), but Gambella's proportion of the settler population is much larger.

The study has two main objectives: 1) to examine the possible impacts of governmentsponsored resettlement on birthrates in Gambella Administrative Region, and 2) to show the

\footnotetext{
${ }^{1}$ Department of Geography, Sonoma State University, USA

${ }^{2}$ Department of Epidemiology and Biostatistics, University of California, San Francisco, USA

Corresponding Author: Aynalem Adugna, Email: aynalem.adugna@ dss.ca.gov
} 
usefulness of using a neighboring administrative region with similar demographis, socioeconomic and environmental characteristics as control (Figure 1).

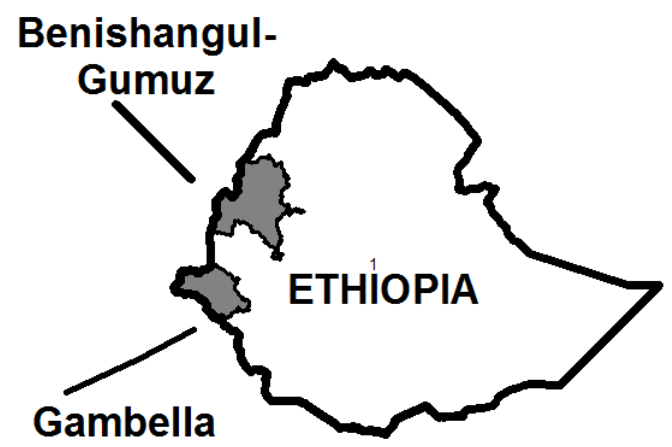

Figure 1: Map showing the study and control areas

Table 1: Number and percentage of women respondents in Gambella, Benishangul- Gumuz, and nationally by 5 year age group (Ethiopian Demographic Survey, 2011)

\begin{tabular}{crrrrrr}
\hline & \multicolumn{2}{c}{ Nation } & \multicolumn{2}{c}{ Benishangul-Gumuz } & \multicolumn{2}{c}{ Gambella } \\
5-year age groups & Number & Percent & Number & Percent & Number & Percent \\
& & & & & & \\
\hline $\mathbf{1 5}-\mathbf{1 9}$ & 3,835 & 23.22 & 554 & 24.83 & 166 & 20.15 \\
$\mathbf{2 0}-\mathbf{2 4}$ & 3,022 & 18.30 & 412 & 18.47 & 145 & 17.60 \\
$\mathbf{2 5}-\mathbf{2 9}$ & 3,185 & 19.29 & 429 & 19.23 & 165 & 20.02 \\
$\mathbf{3 0} \mathbf{- 3 4}$ & 2,100 & 12.72 & 283 & 12.68 & 132 & 16.02 \\
$\mathbf{3 5} \mathbf{- 3 9}$ & 1,958 & 11.86 & 241 & 10.80 & 98 & 11.89 \\
$\mathbf{4 0} \mathbf{- 4 4}$ & 1,314 & 7.96 & 152 & 6.81 & 65 & 7.89 \\
$\mathbf{4 5}-\mathbf{4 9}$ & 1,101 & 6.67 & 160 & 7.17 & 53 & 6.43 \\
Total & $\mathbf{1 6 , 5 1 5}$ & $\mathbf{1 0 0 . 0}$ & $\mathbf{2 , 2 3 1}$ & $\mathbf{1 0 0 . 0}$ & $\mathbf{8 2 4}$ & $\mathbf{1 0 0 . 0}$ \\
\hline
\end{tabular}

\section{MATERIALS AND METHODS}

We used a longitudinal approach and a point-intime multivariate analysis in which women were placed in five-year age cohorts. The sample-based DHS 2000, 2005, and 2011 data were obtained from http://dhsprogram.com/data/dataset admin/login_main.cfm following an online application for download. The enumeration areas in Ethiopia's last two censuses served as the sampling frame (1-3). Complete SAS and GIS/GPS data sets were downloaded. There were 876 women between the age of 15-49 in Gambella's 2000 sample, 921 women in the 2005 sample, and 1,215 women in the 2011 sample. Three variables were analyzed: 1) age of women at the birth of the first child, 2) the number of children born within five years of the 2000 and 2005 surveys, and 3) the number of children ever born. The 2000 and 2005 DHS have duration of residence information but the 2011 DHS does not. Six records with missing duration of residence values were excluded in the 2000 sample, and 11 cases were excluded in the 2005 sample. Comparable DHS data were used for the control region Benishangul-Gumuz.

The statistical software SAS was used to conduct a multivariate analysis of variance (MANOVA). MANOVA is simply an analysis of variance (ANOVA) with two or more dependent variables. Whereas ANOVA tests for the difference in means between two or more groups, MANOVA tests for the difference in two or more 
vectors of means (21). Wilk's Lambda is one of the measures. It can be interpreted as the proportion of the variance in the outcomes that is not explained by an effect (21). To calculate Wilk's Lambda for each characteristic root, one has to calculate $1 /(1+$ the characteristic root $)$, then find the product of these ratios. Pillai's Trace is the other measure (21). To calculate Pillai's trace, each characteristic root is divided by $1+$ the characteristic root, and then the sums of these ratios are summarized. Hotelling-Lawley Trace is very similar to Pillai's Trace. It is the sum of the roots of the product of the sum-of-squares matrix of the model and the sum-of-squares matrix of the error for the two linear regression functions and is a direct generalization of the $\mathrm{F}$ statistic in ANOVA (21). The Hotelling-Lawley Trace is calculated by summing the characteristic roots listed in the output. Roy's Greatest Root is the largest of the roots of the product of the sum-ofsquares matrix of the model and the sum-ofsquares matrix of the error for the two linear regression functions. The value of Roy's Greatest Root is the largest of the characteristic roots. Because it is a maximum, it can behave differently from the other three test statistics. As a general rule, in instances where the other three are not significant and Roy's is significant, the effect should be considered non-significant (Table 1).

\section{RESULTS}

Age distribution of sample women: Figure 1 shows the percentage distribution of sample women in the 2011 DHS by five-year age groups. Differences in age distribution between women interviewees nationally, those in Gambella and those in Benishangul-Gumuz were not statistically significant (Figure 1). The proportion of women under 30 years of age was $60.8 \%$ nationally, $62.5 \%$ in Benishangul-Gumuz, and $57.8 \%$ in Gambella. The main difference is in the length of time various age cohorts of women had lived in their places of interview by the time of DHS 2011. Analysis of data from all three surveys showed significantly higher proportions of nonnatives in Gambella's 2011 DHS than nationally or in Benishangul-Gumuz.
Duration of residence: Results of DHS 2000 show that 15-19 year old nonnatives represented $20.1 \%$ of the population nation-wide, $19.1 \%$ in Benishangul-Gumuz, and $41.8 \%$ in Gambella. For 20-24 year olds, the proportions of nonnatives at the national level, in Benishangul-Gumuz, and in Gambella were 35.3, 29.6 and $66.6 \%$ respectively, suggesting a minority status for 20-24 year old females in Gambella but not nationally or in Benishangul-Gumuz. For the 25-29 year old females, the respective proportions of nonnative females were $42.7,39.0$, and $65.6 \%$. Nonnative 30-34 year old females were also a majority in Gambella $(54.4 \%)$ but a minority nationally (43.7\%) and in Benishangul-Gumuz (45.6\%).

By the time of DHS 2000, the proportion of females residing in places of interview for less than 10 years was $28.0 \%$ nationally, $23.2 \%$ in Benishangul-Gumuz, and $44.0 \%$ in Gambella. The proportions with length of stay between 10 and 19 years were $7.0 \%$ nationally, $5.6 \%$ in BenishangulGumuz, and $12.6 \%$ in Gambella.

Duration of residence and age of respondents at the birth of their first child: The dots in Figure 2 show how old an individual female interviewee was at the birth of her first child. The line graphs show the average age of women at the birth of the first child by duration of residence. A focus on the extreme age groups (15-19 and 45-49) reveals generational differences in the effect of duration on age at first birth. Three observations emerge: a) in both Gambella and Benishangul-Gumuz, there is no difference in age at first birth between natives and nonnatives for the 15-19 age group, b) in both Gambella and Benishangul-Gumuz, there is a difference in age at first birth between natives and nonnatives for the 45-49 age group and c) the difference is in opposite directions with native 4549 year olds having a lower average age at first birth than nonnatives in any duration group in Gambella while nonnatives had a higher age at first birth than natives in any duration group in Benishangul-Gumuz. The effect of duration of residence on age at first birth in Gambella is statistically significant $(\mathrm{p}<.0001)($ Table 1$)$. 


\begin{tabular}{lllll}
\hline Legend & & & & \\
Age group & $1: 15-19$ & $2: 20-24$ & $3: 25-29$ & $4: 30-34$ \\
Duration (years) & $1:$ Native & $2: 0-9$ & $3: 10-19$ & $4: 20+$
\end{tabular}
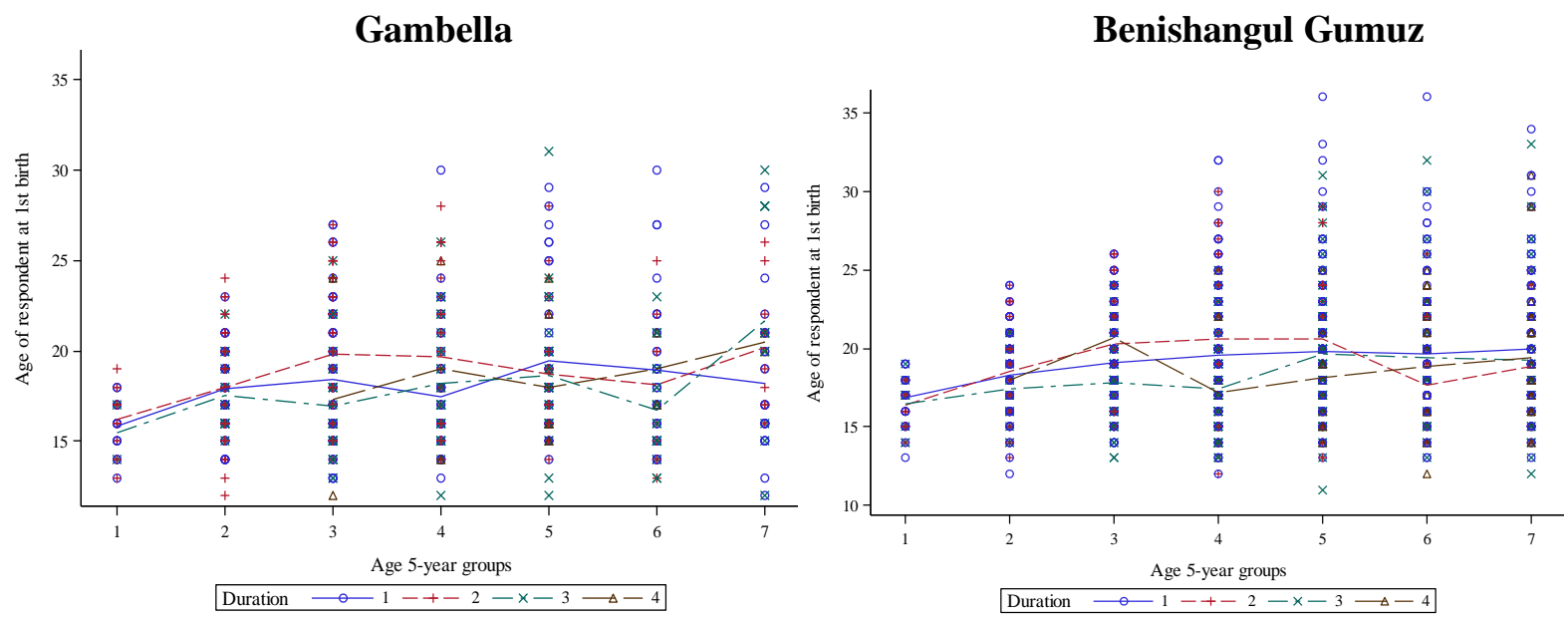

Figure 2: Age of respondent at first birth by age at the time of survey and duration of residence (DHS, 2000)

Duration of residence and childbearing during the five years prior to DHS 2000: One fifth (20.7 $\%$ ) of respondents had two or more births during the five years prior to DHS 2000 nationally, $24.9 \%$ in Benishangul-Gumuz and $15.6 \%$ in Gambella. On the other hand, the proportion of female respondents who only had one birth during that period was $26.5 \%$ nationally, $26.7 \%$ in Benishangul-Gumuz, and $36.6 \%$ in Gambella. For Gambella, the difference by duration of residence is statistically significant $(\mathrm{p}<.0001)$ (Table 1). Figure 3 reveals significant effect of duration of residence in Gambella, but not in BenishangulGumuz.

\section{Legend}

Age group

$$
1: 15-19
$$

$2: 20-24$

Duration (years)

1: Native 2: 0-9

$3: 25-29$

3: $10-19$

$4: 30-34$

Gambella

Benishangul-Gumuz
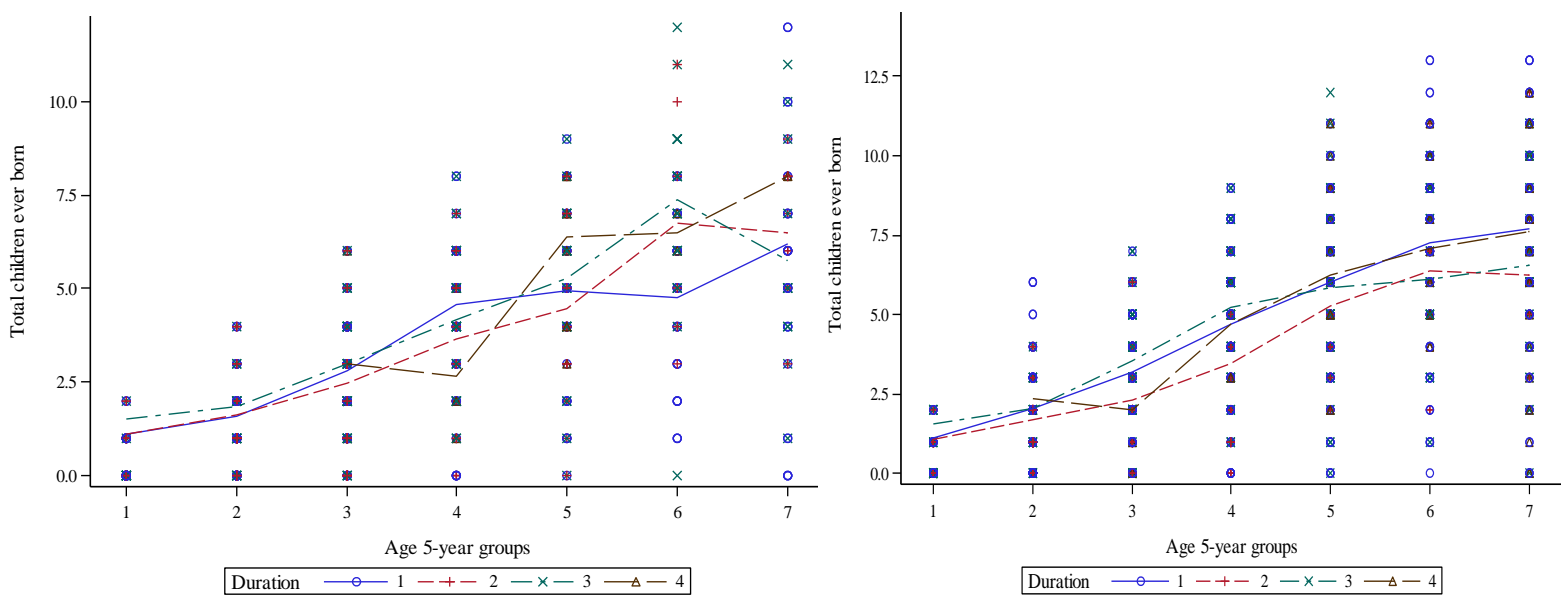

Figure 3: Total children ever born by age at the time of survey and duration of residence 
Nonnatives in the 30-34 age group were between the ages of 10 and 14 at the time of arrival prior to 1980. The 2.0 children per woman deficit for the 30-34 year-olds at DHS 2000 could be explained by the disruptive effects of resettlement. There is no native-nonnative difference for the two age groups in Benishangul-Gumuz. The nativenonnative difference in Gambella also applies to the $35-39,40-44$ and $45-49$ year age groups, with nonnatives reporting approximately two additional lifetime births than natives. This pattern is largely absent in Benishangul-Gumuz, where most curves representing the average number of children by women's age and duration cohorts are overlapping (Figure 4).

\begin{tabular}{lllll}
\hline Legend & & & & \\
Age group & $1: 15-19$ & $2: 20-24$ & $3: 25-29$ & $4: 30-34$ \\
Duration (years) & $1:$ Native & $2: 0-9$ & $3: 10-19$ & $4: 20+$
\end{tabular}

Gambella

Benishangul Gumuz
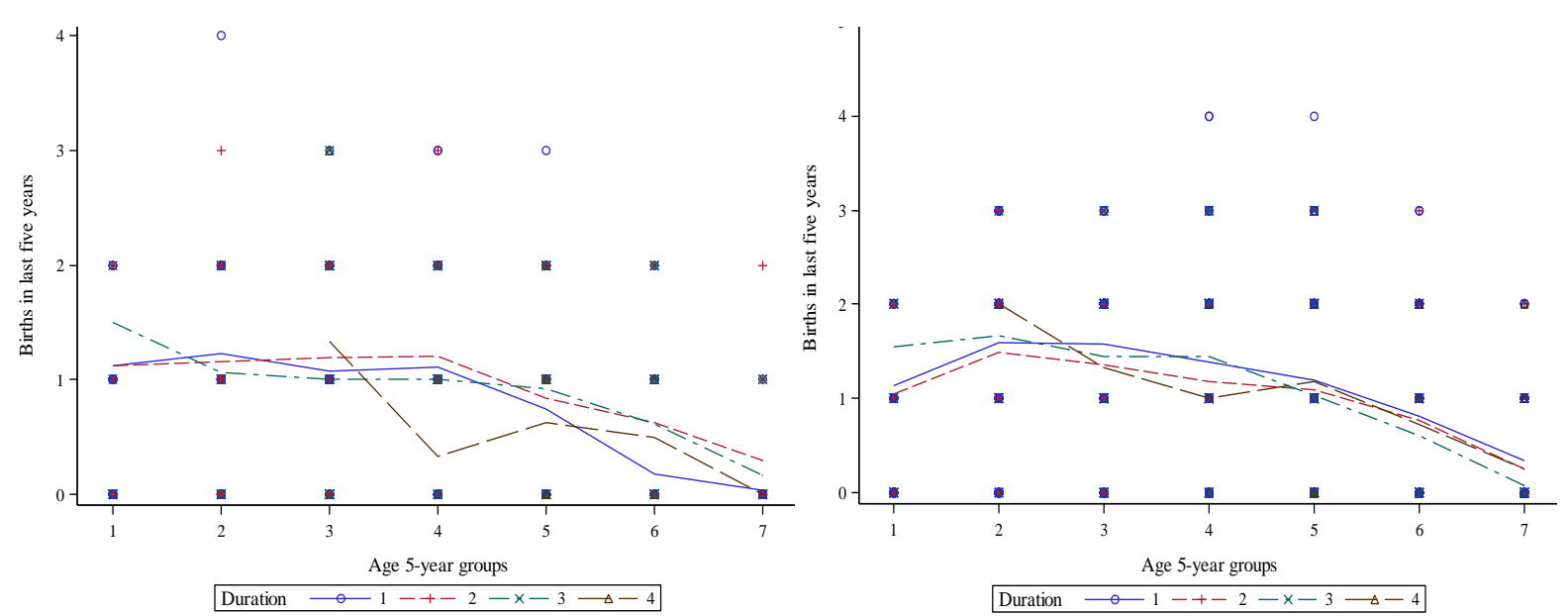

Figure 4: Number of births in the five years prior to DHS 2000 by age and by duration of residence

Figure 5 presents a comprehensive longitudinal picture. The table portion combines findings from all the three demographic surveys by using the number of births in the last five years variable for the entire 16-year period (the five years preceding DHS 2000 to the end of DHS 2011), and by tracking age cohorts of women. The six-yearinterval for 2005 to 2011 was made possible by reclassification of single age distributions using SAS. This approach provided an opportunity to follow recent reproductive histories of an age cohort using the number of births in the last five years variable as proxy. The graph portion of Figure 5 shows the percentages of women who had two or more births in the five years prior to DHS 2000, DHS 2005, and DHS 2011. Gambella's position during the three surveys is noteworthy for the shift from a bottom position in 2000 to the second highest in 2011. For instance, $43.9 \%$ and $23.3 \%$ of women aged 25-29 in Benishangul-Gumuz and Gambella had two or more births respectively during DHS 2000. At $33 \%$ each, the proportions for the two regions had become equal by DHS 2011. 

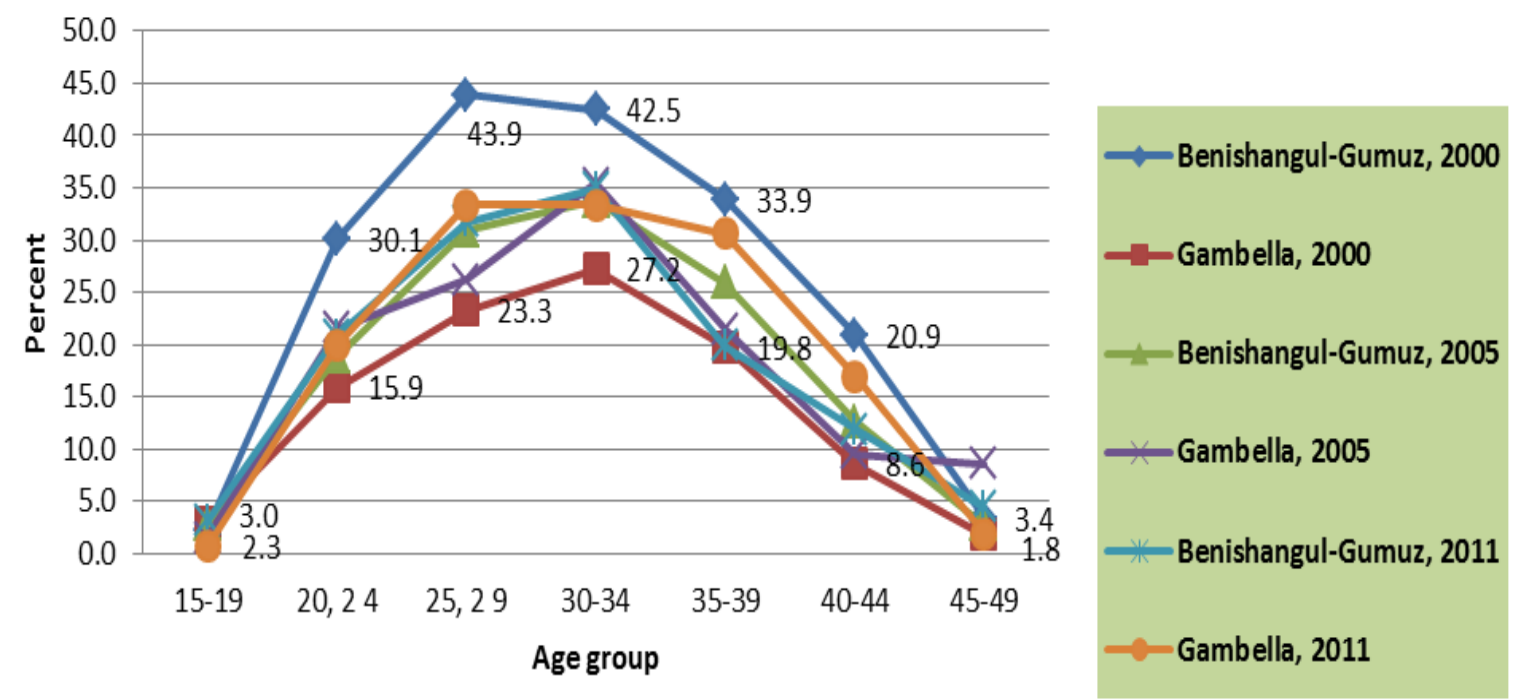

Figure 5: Percentage of women who had two or more births in the five years prior to DHS 2000, DHS 2005, and DHS 2011 (top graph) and the number of children born per woman by age group of respondents between 1995 and 2011 (bottom table)

Table 2: Number of births per woman in DHS 2000, 2005, 2011 by age group of respondents

\section{Benishangul-Gumuz}

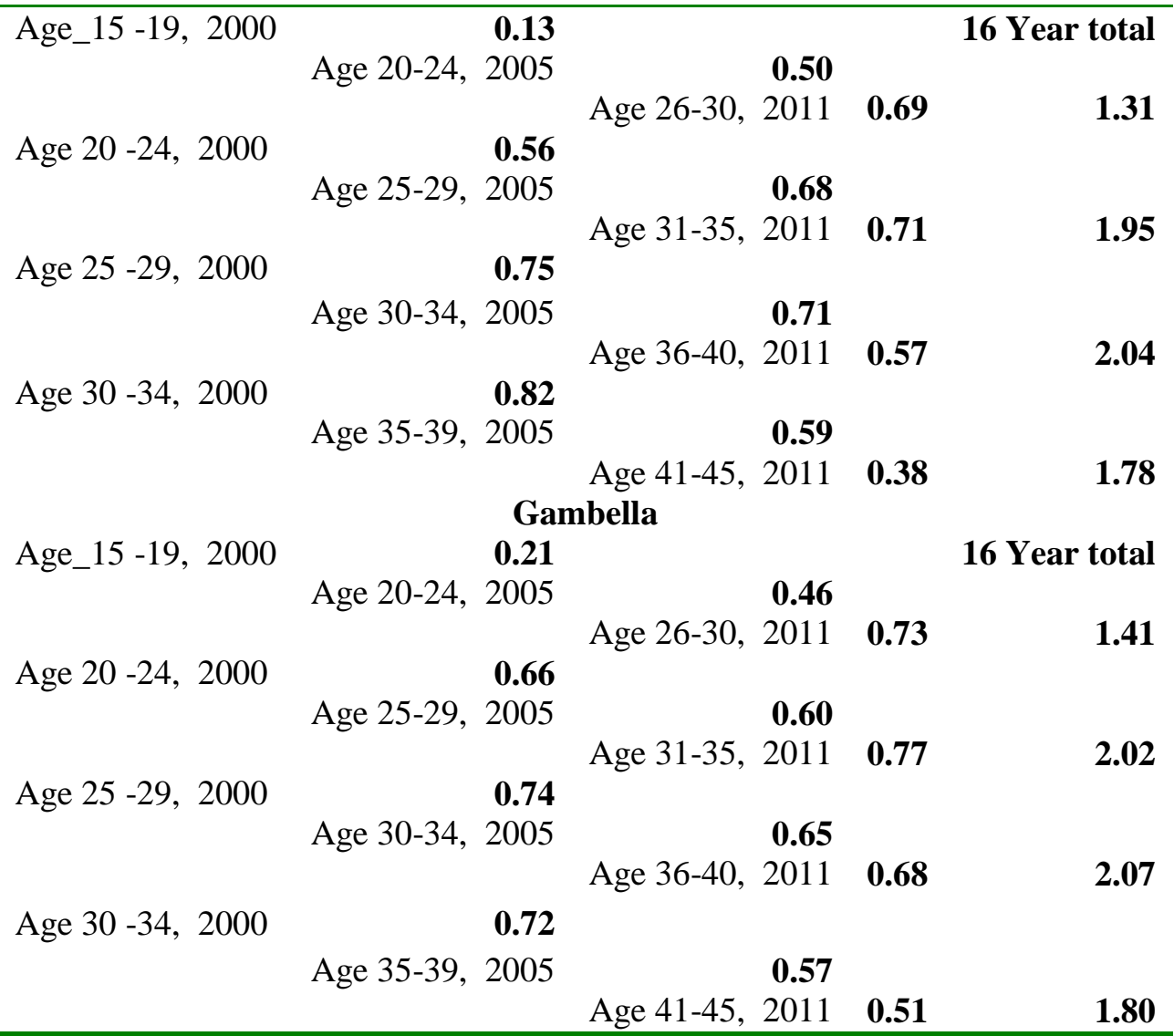


Univariate and multivariate analyses of variance: A summary univariate analysis based on a point-in-time DHS 2000 data is provided for Gambella followed by a multivariate analysis of variance (MANOVA) (Table 1). Results of the MANOVA with all the three dependent variables in combination and the duration of residence as the independent variable show a statistically significant effect. MANOVA calculates four multivariate test statistics based on the characteristic roots (21). The null hypothesis for each of these tests is the same: the independent variable has no effect on any of the dependent variables. Duration of residence (coded V013) is the independent variable in both the univariate and the multivariate analysis. The first dependent variable considered was total number of children ever born (code V201). We obtained an R-Square of 0.53 , a Root MSE of 1.65 , a coefficient of variation of 45.20 and a mean value of 3.65. The second dependent variable in the univariate analysis was number of births in the five years prior to DHS 2000 (code V208), giving a RSquare of 0.24, a Root MSE of 0.67, a coefficient of variation of 72.48 and a mean of 0.92 . The third dependent variable in the univariate analysis was age of respondent at first birth (code V212) (RSquare 0.11, Root MSE 3.47, coefficient of variation 18.88, Mean of 18.42). All three results were statistically significant $(\mathrm{p}<0.0001)$ (Table $1)$.

Table 3. Analysis of Variance with age at first birth, children born within 5 years of DHS 2000, and the number of children ever born as dependent variables and duration of residence as the independent variable: Gambella DHS 2000

Analysis of Variance: One Dependent and one Independent Variable Independent Variables = Duration of residence (V013)

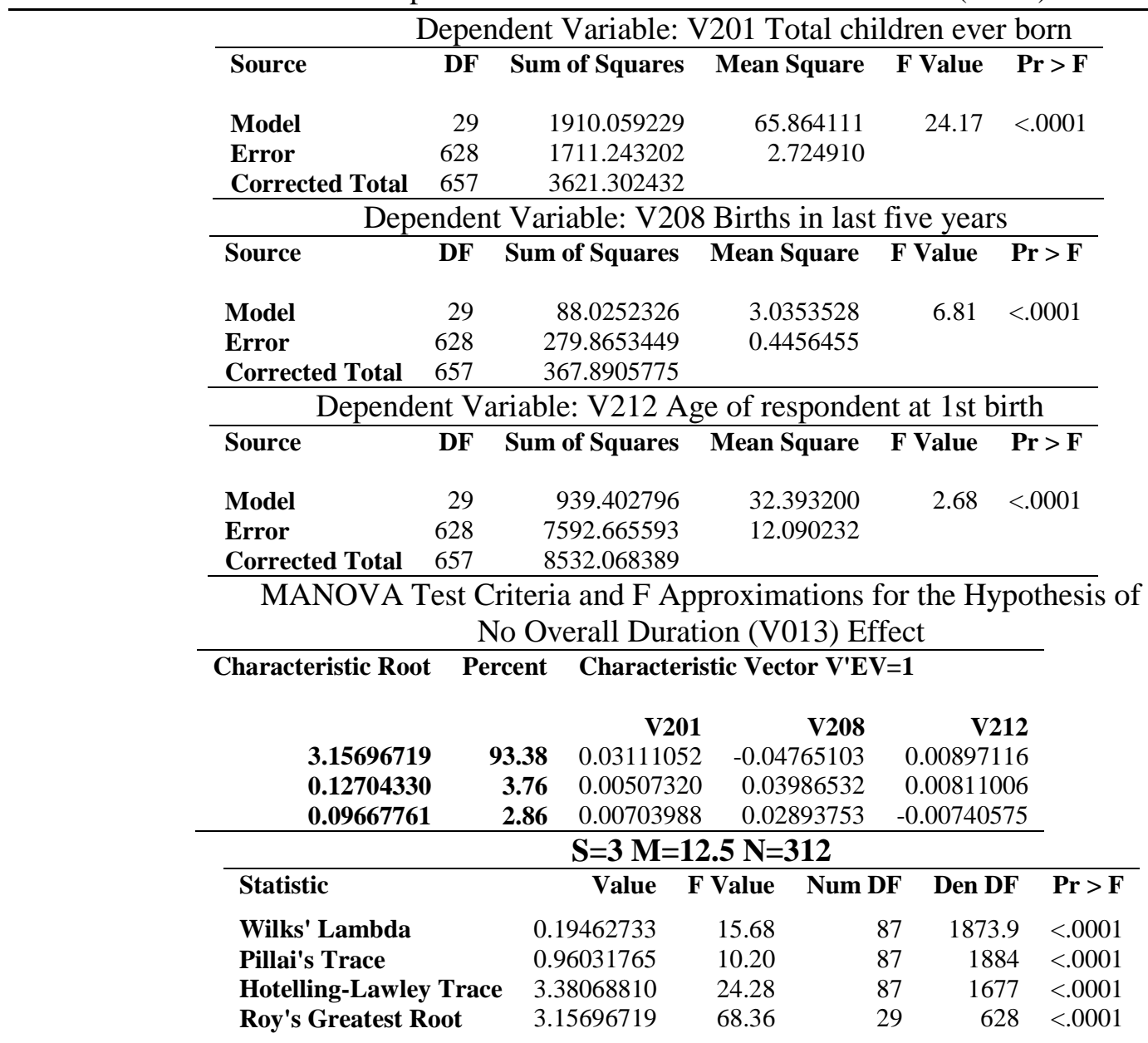

NOTE: F Statistic for Roy's Greatest Root is an upper bound. 


\section{DISCUSSION}

No studies are available regarding the impacts of large scale resettlement on birth rates. By achieving its two main objectives of showing the fertility effects of resettlement in Gambella and of demonstrating the advantages of using a neighboring region as control, this study can help fill the knowledge gap. We adopted a dual approach of longitudinal age-cohort tracking on the one han and a point-in-time multivariate analysis on the other, to examine the possible demographic impacts of resettlement in Gambella Region. Both the dual approach and the use of Benishangul-Gumuz as control represent a methodological improvement in the analysis of DHS data. Our overall finding is that resettlement has the effect of reducing the number of lifetime births for women who arrived at young ages, but not on women who were past the mid-point of their reproductive years at the time of arrival. The effect of resettlement on women just coming into marriageable ages at the time of arrival is unlikely to be the singular reason Gambella has a lower total fertility rate (TFR) than Benishangul-Gumuz (1-3). We are not able to show whether or not settler-native differentials existed in contraceptive prevalence (5), or if Gambella's sociopolitical factors $(13,15,16$ and 18) differentially affected birth rates among settlers.

We analyzed reproductive histories using a count of lifetime births and recent fertility based on the 16-year period starting with five years prior to DHS 2000 and ending at the conclusion of DHS 2011. The picture for Gambella is complex, and specific results depended on whether the focus was on cumulative numbers of lifetime births or on recent fertility. Our analysis traced the reproductive histories of the 1970s and 80s arrivals based on age at the time of DHS 2000. The comparison between women in the 30-34 and 40-44 age groups is particularly noteworthy. For 40-44 year-olds, the total number of births is higher among nonnatives in the 20+ duration group than among natives by about 1.5 lifetime births per woman. The reverse is true for 30-34 year olds in the 20+ years' duration group. Here, natives have about 2.0 additional lifetime births than nonnatives. This is not surprising given that nonnatives in the 30-34 age groups were aged 1014 at the time of arrival prior to 1980 . The 2.0 lifetime births per woman deficit for the 30-34 year old nonnatives could be thought of as resulting from the disruptive effects of resettlement. Supporting evidence comes from the absence of native-nonnative differences for the two age groups in our control region, Benishangul-Gumuz. The higher cumulative lifetime births in Gambella also apply to 35-39, 40-44 and 45-49 year-olds where approximately two additional births were registered for nonnatives than for natives. This difference is largely absent in Benishangul-Gumuz. In other words, the disruptive effect of resettlement on child birth was limited to women who were younger than 35 years of age at DHS 2000. Settler women aged 40 or higher at DHS 2000 had higher lifetime births in any duration group than native born women. These findings do not apply to Benishangul-Gumuz where native-born women have higher lifetime births than nonnatives in any age or duration group.

A different portrait emerges when recent reproductive performances (births in the five years preceding the three surveys) are analyzed. The picture from Gambella's DHS 2000 is one of an initial deficit for age cohorts of nonnatives compared to natives; a deficit which is then made up over a period of 16 years (five years prior to DHS 2000 through the end of DHS 2011).

Results of the multivariate analysis with duration of residence as the independent variable and three dependent variables (age at the time of first birth, number of births in the five years within five years of the 2000 and 2005 surveys and lifetime births) showed a statistically significant effect of duration of residence when based on a point-in-time analysis of Gambella's DHS 2000. However, a longitudinal age cohort analysis showed the duration effect as moderating over time. The moderation is reflected in the absence of significant native-nonnative differences in the number of children ever born when five-year age cohorts are followed from DHS 2000 to the DHS 2011.

The longitudinal approach followed in Figure 5 shows the success settler women in Gambella achieved in making up for the deficits recorded in DHS 2000. The right most columns for Gambella and Benishangul-Gumuz reveal this. For example, 20-24 year old females in Benishangul-Gumuz started with a five-year 
average of 0.66 births in 2000 and ended with a cumulated total of 2.02 births for the 16 year period (five years prior to DHS 2000 through DHS 2011). Their counterparts in Gambella started with a lower five year average of 0.56 in 2000 but had matched the 16-year cumulated total for women in Benishangul-Gumuz by the end of the 16-year period in 2011.

We recommend that the length of stay variable be reinstated in Ethiopia's future DHS surveys to capture the effects of population mobility on birth rates and other demographic variables. Monitoring of the possible impacts of mobility on health and death is also dependent on the inclusion of the length of stay variable.

\section{REFERENCES}

1. CSA and ORC Macro. Ethiopia Demographic and Health Survey 2000. Addis Ababa, Ethiopia, Central Statistical Agency and Calverton, Maryland, ORC Macro, 2001.

2. CSA and ORC Macro. Ethiopia Demographic and Health Survey 2005. Addis Ababa, Ethiopia, Central Statistical Agency and Calverton, Maryland, ORC Macro, 2006.

3. CSA and ORC Macro. Ethiopia Demographic and Health Survey 2011. Addis Ababa, Ethiopia, Central Statistical Agency and and Calverton, Maryland, ORC Macro, 2012.

4. Byass P, Alemayehu Worku, Anders E, Yemane Berhane. DSS and DHS: longitudinal and cross-sectional viewpoints on child and adolescent mortality in Ethiopia. Popul Health Metrics 2007; 5:12.

5. Mengistu Asnake, Henry EG, Yewondwossen Tilahun, Oliveras E. Addressing unmet need for long-acting family planning in Ethiopia: Uptake of single-rod progestogen contraceptive implants (Implanon) and characteristics of users. Int $\mathbf{J}$ Gynec Obstetr 2013; 123: e29-e32.

6. Yared Mekonnen, Tensou, B., Daniel S. Telake, Tedbabe Degefie, Abeba Bekele. Neonatal mortality in Ethiopia: trends and determinants. BMC Public Health 2013; 13:483.

7. Ethiopian Society of Population Studies (2005). Gender Inequality and Women's Empowerment: In-depth Analysis of the EDHS 2005. In-depth Analysis of the
Ethiopian Demographic and Health Survey 2005. Addis Ababa, October 2008. Available at http://countryoffice.unfpa.org/ethiopia/ drive/Gender.pdf. Retrieved on August 13, 2014

8. Arimond $\mathrm{M}$ and Ruel $\mathrm{M}$ T. Progress in Developing an Infant and Child Feeding Index: An Example Using the Ethiopia Demographic and Health Survey 2000. FCND Discussion Paper No. 143. Washington DC, Food Consumption and Nutrition Division. International Food Policy Research Institute, December 2002.

9. Woldemariam Girma and Timotiows Genebo. Determinants of Nutritional Status of Women and Children in Ethiopia. Calverton, Maryland, USA, ORC Macro Calverton, and Addis Ababa, Health and Nutrition Research Institute, 2002.

10. Samson Gebremedhin. Trend and sociodemographic differentials of Caesarean section rate in Addis Ababa, Ethiopia: Analysis based on Ethiopian demographic and health survey data. Repr Health 2014; 11:14.

11. Johnson K, Peterman A. Incontinence Data from the Demographic and Health Surveys: Comparative Analysis of a Proxy Measurement of Vaginal Fistula and Recommendations for Future PopulationBased Data Collection. DHS Analytical Studies 17. United States Agency for International Development, Macro International Inc. and University of North Carolina. November, 2008.

12. Baumgartner P, Braun VB, Degnet A, Müller M. Impacts of large-scale land investments on income, prices, and employment: Empirical analyses in Ethiopia. Presented at the Annual World Bank Conference on Land And Poverty. Washington DC, World Bank, April 8-11, 2013.

13. Medhane Tadesse. Gambella. The impact of local conflict on regional security. ISS Africa, Institute for Security Studies. Pretoria, South Africa (no date). Available at www.issafrica.org/uploads/CPDRPAPERGA MBELLA.PDF. Retrieved on November 14, 2014.

14. Ojulu OO, Asfaw M. A critical and comparative analysis of political empowerment/representation/ in promoting 
gender equality in Gambella Regional State. Developing Country Studies 2014; 4:78-95.

15. Dereje Feyissa. A national perspective on the conflict in Gambella. In: Proceedings of the 16th International Conference of Ethiopian Studies (Ege S, Aspen H, Birhanu Teferra, Shiferaw Bekele, eds), Trondheim, 2009: 114. Available at http://portal.svt.ntnu.no/ sites/ices16/Proceedings. Retrieved on August 17, 2014.

16. The International Human Rights Law Clinic. The Anuak of Gambella, Ethiopia. Shadow Report submitted by the International Human Rights Law Clinic, Washington College of Law, Washington DC, USA in collaboration with the Anuak Justice Council Saskatoon, Saskatchewan, Canada, March, 2007.

17. UNOCHA. Eastern Africa: Displaced Populations Report. Issue 14, 30 September 2012 - 31 March 2013. April, 2011. Nairobi, Kenya. Available at http://reliefweb.int/sites/reliefweb.int. Retrieved on November 12, 2014.

18. Global IDP. Profile of internal displacement. Ethiopia: compilation of the information available in the Global IDP Database of the Norwegian Refugee Council (as of 13 July, 2004). Available at http://www.idpproject.org. Retrieved on August 26, 2014.

19. The Federal Democratic Republic of Ethiopia. Ministry Of Water Resources. National Meteorological Agency. Climate Change National Adaptation Programme of action (NAPA) of Ethiopia. June, 2007. Addis Ababa, Ethiopia. Available at http://unfccc.int/resource/docs/napa/eth01.pdf. Retrieved on September 29, 2014.

20. CSA. Population and Housing Census ReportCountry - 2007. Addis Ababa, Central Statistical Agency. Available athttp://www.csa.gov.et/newcsaweb/images/ documents/surveys/Population $\% 20$ and $\% 20 \mathrm{Ho}$ using\%20census/ETH-pop2007/survey0/data/Doc/Reports/National_Stat istical.pdf. Retrieved on October 2, 2014.

21. UCLA Institute for Digital Research and Education. Data analysis guidelines available at https://idre.ucla.edu. Retrieved on August 9, 2015. 